5. Tsakris A, Poulou A, Pournaras S, et al. A simple phenotypic method for the differentiation of metallo- $\beta$-lactamases and class A KPC carbapenemases in Enterobacteriaceae clinical isolates. $J$ Antimicrob Chemother 2010;65(8):1664-1671.

6. van Dijk K, Voets GM, Scharringa J, et al. A disc diffusion assay for detection of class A,B and OXA-48 carbapenemases in Enterobacteriaceae using phenyl boronic acid, dipicolinic acid and temocillin. Clin Microbiol Infect doi:10.1111/1469-0691.12322. Published July 4, 2013.

7. Venkatachalam I, Teo J, Balm MN, Fisher DA, Jureen R, Lin RT. Klebsiella pneumoniae Carbapenemase-producing enterobacteria in hospital, Singapore. Emerg Infect Dis 2012;18(8):1381-1383.

\section{Endotoxin Overproduction of Enterobacter cloacae and Mortality Rate}

To the Editor-We want to applaud the great work done by Arduino et $\mathrm{al}^{1}$ in their article that established growth rates and endotoxin production in vitro in propofol using $10 \mathrm{clin}$ ically important microorganisms associated with outbreaks that have been implicated in extrinsic contamination of this intravenous anesthetic, as published by the Centers for Disease Control and Prevention in May and June $1990 .^{2}$ We would like to mention other studies that were reported after Arduino et $\mathrm{al}^{1}$ to lend additional credence to their findings. According to the analysis by Arduino et $\mathrm{al}^{1}{ }^{1}$ endotoxin was not detected in the gram-negative cultures at the start of the experiment, but after 24 hours, endotoxin production increased rapidly to a substantial level. Enterobacter cloacae was the best endotoxin producer of all of the microorganisms tested at all time points $(2,412-4,820 \mathrm{ng} / \mathrm{mL}$ in 24 hours; $9,420-18,840 \mathrm{ng} / \mathrm{mL}$ in 48 hours; $7,360-14,720 \mathrm{ng} / \mathrm{mL}$ in 72 hours). Translating these results to clinical practice, 11 years later, Weist et al $^{3}$ reported outbreaks caused by multiple dose vials from 1983 to 2002, including 2 fatalities and 4 infected patients whose cases were associated with the administration of propofol contaminated by nothing more and nothing less than E. cloacae. Additionally, Mattner and Gastmeier ${ }^{4}$ refer to E. cloacae and Serratia marcescens as the microbial species most commonly associated with death in the 7 reported outbreaks associated with propofol use.

We would again like to congratulate Arduino et $\mathrm{al}^{1}$ for the practical knowledge generated by this study, which focused on specific strains that overproduce endotoxin, such as $E$. cloacae. Consequently, this species has been shown to be associated with a high mortality rate, as reported in several studies. ${ }^{3,4}$

\section{ACKNOWLEDGMENTS}

Potential conflicts of interest. All authors report no conflicts of interest relevant to this article. All authors submitted the ICMJE Form for Disclosure of Potential Conflicts of Interest, and the conflicts that the editors consider relevant to this article are disclosed here.

\section{Carolina Zorrilla-Vaca, MD; ${ }^{1}$ Andrés Zorrilla-Vaca, $\mathrm{MD}^{2}$}

Affiliations: 1. Health Faculty, University of Libre, Cali, Colombia;

2. Health Faculty, University of Valle, Cali, Colombia.

Address correspondence to Carolina Zorrilla-Vaca, MD, Diagonal 37, No. 3-29, Health Faculty, University of Libre, Cali 760026, Colombia (carito906@hotmail.com).

Infect Control Hosp Epidemiol 2014;35(5):601-601

(C) 2014 by The Society for Healthcare Epidemiology of America. All rights reserved. 0899-823X/2014/3505-0027\$15.00. DOI: $10.1086 / 675845$

\section{REFERENCES}

1. Arduino A, Bland L, McAllister S, et al. Microbial growth and endotoxin production in the intravenous anesthetic propofol. Infect Control Hosp Epidemiol 1991;12:535-539.

2. Centers for Disease Control and Prevention. Postsurgical infections associated with an extrinsically contaminated intravenous anesthetic agent-California, Illinois, Maine, and Michigan, 1990. MMWR Morb Mortal Wkly Rep 1990;39(25):426-427, 433. http://www.cdc.gov/mmwr/preview/mmwrhtml/00001653.htm. Accessed January 1, 2014.

3. Weist K, Wilbrandt B, Herm T, Halle E, Melzer C, Ruden H. Severe cases of sepsis in an outpatient clinic causes by contaminated intravenous propofol. In: Program and abstracts of the Annual Meeting of the German Society for Hygiene and Microbiology (DGHM); Heidelberg, Germany; 2002 (Abstract).

4. Mattner F, Gastmeier P. Bacterial contamination of multiple-dose vías: a prevalence study. Am J Infect Control 2004;32:12-16.

\section{Different Compliance with Central Line Insertion Bundle between Intensivist and Nonintensivist Staff in Intensive Care Units}

To the Editor-The use of central venous catheter (CVC) is increasing for monitoring hemodynamic status and providing venous access in the intensive care unit (ICU). However, as CVC use increases, complications of central line-associated bloodstream infection (CLABSI) after the insertion of CVCs increase as well and become another important cause of morbidity and mortality. ${ }^{1,2}$ Therefore, several prevention efforts were developed to reduce the occurrence of CLABSI in the clinical setting of the ICU. "Insertion bundles" for reducing the risk of infection during the insertion of CVCs and "maintenance bundles' for minimizing the risk of infection for patients with CVCs are the 2 essential care bundles for prevention of CLABSI. CVC insertion is always performed by physicians in the ICU; however, ICU physicians may be intensivist or nonintensivist staff, and studies that compare CVC insertion bundle compliance of these 2 different types of physicians in the ICU are scarce. Therefore, this study was conducted to investigate the physician factors associated with CVC insertion compliance in the ICU. 